\title{
Chuukese Migrant Women in Guam: Perceptions of Barriers to Health Care
}

Asian/Pacific Island Nursing Journal

Volume 1(3): 19-28

(C)Author(s) 2017

http://digitalscholarship.unlv.edu/apin/

\author{
Margaret Hattori-Uchima ${ }^{a}$
}

\begin{abstract}
This descriptive qualitative study examined perceived barriers to health care among Chuukese migrant women in Guam and explored which factors influenced health-seeking behaviors. Study participants recommended interventions which may reduce those perceived barriers. Since the Compact of Free Association with the United States was enacted in 1985, there has been a dramatic rise in the numbers of Chuukese migrating to Guam. This migration is anticipated to continue with more migrants needing health care, education, and social services. Little is known about their perceptions of barriers to health care services or the cultural, social, economic, and other factors that influence their health-seeking behaviors.

Focus group interviews provided rich data, which were analyzed using content analysis. Themes included barriers to seeking and maintaining health and social and cultural factors influencing health-seeking behaviors. Major barriers identified were financial issues, difficulty in obtaining care due to long wait times, transportation problems, and struggles with both language and cultural nuances of communication. It was found that the women identified a mistrust of health and social services resulting from communication barriers. Social and cultural factors included the use of traditional Chuukese medicines, lack of preventive care services, confidentiality concerns, and feelings of mistreatment. Participants made recommendations for improved care and expressed a strong desire to achieve the mutual goal of better health care for Chuukese migrants in Guam.
\end{abstract}

Keywords: Chuukese, health disparities, marginalization, migrant women, health-seeking

Since the implementation of the Compact of Free Association with the United States in 1985, large numbers of migrants from the nearby Micronesian islands have relocated to Guam (Greico et al., 2003). Micronesian migrants in Guam experience disparities in several areas of health and socioeconomic statuses, such as higher rates of poverty, lower educational levels, and lower rates of prenatal care (Guam Bureau of Statistics and Plans, 2005, 2015; Guam Housing and Urban Renewal Authority, 2016). Data from Guam revealed higher rates of diabetes during pregnancy and increased risk of delivering large for gestational age infants (Alur et al., 2002). In 2004, of the women in Guam who did not receive any prenatal care, the largest racial group lacking prenatal care $(46.8 \%)$ were those from the Federated States of Micronesia (Guam Bureau of Statistics and Plans, 2005).

The purpose of this study was to examine perceived barriers to health care among Chuukese migrant women in Guam, to examine what factors may influence their health-seeking behaviors, and to identify interventions recommended by the Chuukese migrant women, which may reduce those perceived barriers to health care. This is necessary as studies on the Chuukese people and health-seeking behaviors are limited (Shoultz, Magnussen, Hansen, Selifis, \& Ifenuk, 2007; Tan, Haumea, Juarez, \& Grimm, 2014; Wong \& Kawamoto, 2010).

The Compact of Free Association Act of 1985 established a relationship with the Federated States of Micronesia and the Republic of the Marshall Islands. In 1994, the Republic of Palau was included in the Compact. These three countries are collectively referred to as the Freely Associated States. The compact allows citizens of the Freely Associated States to enter and reside indefinitely in the United States, territories, and possessions freely, without regard to the Immigration and Nationality Act's visa

\footnotetext{
${ }^{a}$ University of Guam, Guam

Corresponding Author:

Margaret Hattori-Uchima, PhD, RN

University of Guam Dean,

School of Nursing and Health Sciences http://www.uog.edu
} 
and labor certification requirements (U.S. General Accounting Office, 2016). The number of Micronesians who migrated to Guam from the Freely Associated States from 1995 to 1996 was 190 persons. The 2010 Census data revealed that this number rose to 22,086 (Government of Guam, 2011). Chuuk is the most populous state of the Federated States of Micronesia, with 59,367 people living in a land area of 49 square miles (Pacific Resources for Education and Learning, 2005). Chuuk is 590 nautical miles southeast of Guam; less than two hours by air (The Salvation Army Western Territory USA, 2003). Migration to Guam from the Federated States of Micronesia continues to grow rapidly due, in large part, to the proximity to Chuuk (Hezel \& Levin, 2012).

Data demonstrates the socioeconomic and health disparities affecting the migrants in Guam. Higher rates of poverty were documented among the compact migrants. In 2003, $45.2 \%$ of migrants in Guam lived below the poverty level with $81.6 \%$ of those below the $185 \%$ poverty level (Guam Bureau of Statistics and Plans, 2015). The number of homeless Chuukese has been increasing in Guam (Guam Housing and Urban Renewal Authority, 2016; The Salvation Army and Guam Housing and Urban Renewal Authority, 2007). In 2007, those who reported Chuukese ethnicity for the head of household accounted for $16.3 \%$ of the homeless in Guam (The Salvation Army and Guam Housing and Urban Renewal Authority, 2007). The numbers in the 2016 Homeless Point in Time Count documented a total of 1,085 persons, with Chuukese comprising the largest ethnic group of homeless at 454 persons; $41.8 \%$ of the total homeless (Guam Housing and Urban Renewal Authority, 2016).

Disparities in cancer incidence among Micronesians are well documented in the Guam Cancer Registry (Haddock, Talon, \& Whippy, 2006; Haddock, Whippy, Talon, \& Montano, 2009). The incidence rates for liver cancer among Micronesians was 39.4 per 100,000 ; significantly higher than the United States at 5.2 per 100,000. Incidence rates for lung cancer and bronchus are almost double for Micronesians compared to those in the United States (111.5 per 100,000 and 70.1 per 100,000 , respectively; Haddock et al., 2009). Mortality rates for all cancers statistics in Guam from 1998 to 2002 revealed that Micronesians had higher mortality rates for liver cancer (43.5 per 100,000) among all ethnic groups compared to the United States (4.9 per 100,000; Haddock et al., 2006).

Cancer incidence data continues to confirm disparities in Guam (The Guam Community Health Assessment, 2014). Specifically, the incidence of lung cancer in Guam from 2003 to 2017 at 88.4 per 100,000 for Chamorros, 34.0 per 100,000 for Filipinos, and 174.7 per 100,000 for Micronesians. Disparities are evident when other health indicators and data are examined. The diabetes mortality rate in Guam was 39.9 per 100,000 compared to the rate in the United States of 22.3 per 100,000 (Guam Department of Public Health and Social Services, 2014). Data have shown that Micronesians in Hawaii suffer disproportionately from diabetes and have a higher prevalence of co-morbidities commonly associated with diabetes (Pobutsy, Krupitsky, \& Yamada, 2009; Tan et al., 2014). Compact migrants in Hawaii also face socioeconomic and health disparities (Pobutsy et al., 2009; Pobutsky, Buenconsejo-Lum, Chow, Palafox, \& Maskarinec, 2005; Yamada \& Pobutsky, 2009).

\section{Chuukese Culture}

An important foundation of Chuukese society is the lineage. Lineage is traced along the female's line consisting of the oldest female and all the women and their children. The definition of family in traditional Chuukese society refers to the matrilineal group rather than the individual nuclear family (Hezel, 1992). The matrilineal group would ideally live together on a single property and function as a unit of its own. Lineage is important for the Chuukese because one's identity is derived from the lineage; women maintain the role of primary caregiver for children and peacekeeper within the family (Moral, 1998).

In Chuukese culture, there is a significant incest taboo. The incest taboo is tied to the relationship between sister and brother. All close male members of a woman's clan are considered her brothers. The incest taboo sets up complex standards of avoidance behaviors and greatly affects the status of women. Brothers must be physically kept away from sisters, and sisters must remove any type of sexual connotation from her behavior, body, and presence. Moral (1998) stated "The ideal behaviour for a sister is to pretend that she is not there (that is the only way for all sexual connotations to disappear)" (p. 276). In Chuukese society, there is an inherent view of male superiority. Although the society is matrilineal, men are considered more capable and stronger than women; women are dependent on the men for protection. The limitations set up by the incest taboo significantly affect the women's ability to speak in public forums, because there will always be brothers present thus creating a culture of silence for women (Moral, 1998).

As Chuukese continue to migrate from Chuuk to Guam, the role of women as protector of the lineage is changing (Hezel, 2001). In the past, the extended family, and in particular, the male relatives, have protected women from harm. As families move out of Chuuk, the nuclear family is not able to provide the same level of protection to women (Shoultz et al., 2007). According to Moral (1998), this loss of protection for women through the lineage has resulted in an acceptance of domestic violence. 
Table 1. Focus Group Question Guide

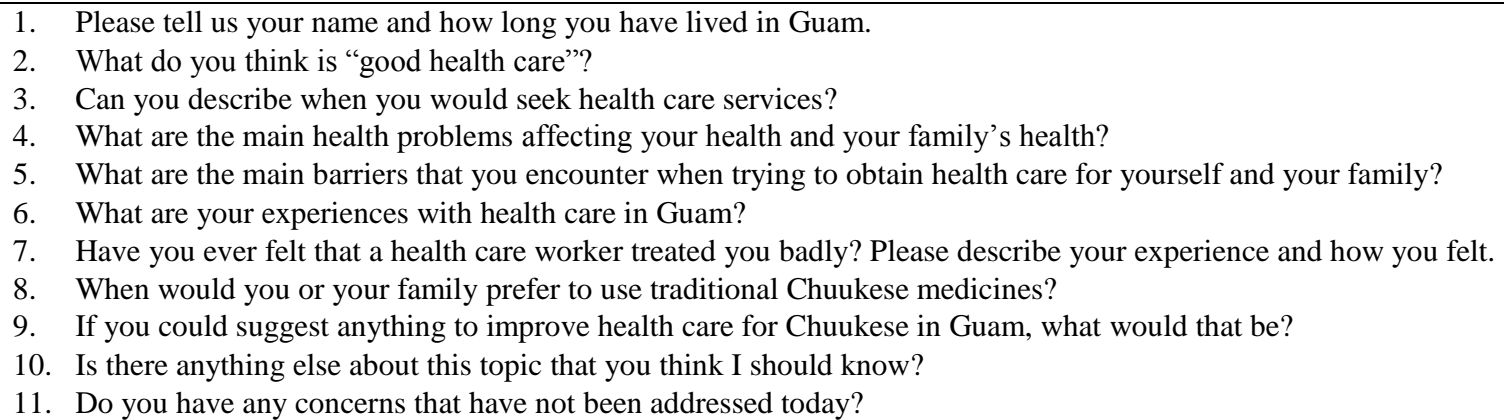

The Chuukese immigrants in Guam and the United States are increasing; however, there is a paucity of research on their perceptions of barriers to health care services or the factors that may influence health-seeking behaviors. This study aimed to increase the knowledge about Chuukese migrants and the understanding of the issue of health disparities.

\section{Methods}

\section{Participants}

A convenience sample of 21 Chuukese women was selected for the focus groups. Participants in each group were known to each other as either close friends or family members. Inclusion criteria included (a) migrant women who have lived in Guam for at least 1 year and (b) were 21 years of age or older. English speaking ability was not a limitation of the study because a translator was available during focus group sessions. Migrants who had not been in Guam for at least 1 year were ineligible because they may not have had adequate exposure to provide information needed about the topic. The settings for the study were the various neighborhood locations where the women lived. Two focus groups were held in common neighborhood meeting areas, and three groups were held in the home of one of the participants in five villages across the island: two northern villages, two southern, and one central village. Participants were recruited with translator assistance using a standard script.

\section{Protection of Human Subjects}

Approval was obtained from the Institutional Review Board at Villanova University (HS 10-029) and from the University of Guam Committee on $\mathrm{Hu}-$ man Research Subjects (CHRS \# 09-31). During the initial participant contact, the researcher explained the purpose of the study, benefits and risks, audio and digital taping of interviews, the voluntary nature of the study, ability of the participant to withdraw at any time or to refuse to answer any questions, steps taken to assure participant confidentiality, and the time commitment of the participant. The researcher provided these explanations in English with a Chuukese translator present to explain in Chuukese for each of the focus group sessions. The researcher implemented and processed informed consent procedures, and reminded participants at the beginning of each group and during return meetings of their right to withdraw at any time. Consent forms were provided in Chuukese and English, with translator assistance during all consenting procedures. A $\$ 25$ gift certificate to a grocery store was provided as an incentive for all participants.

\section{Design}

A descriptive qualitative research approach was chosen to explore the unknown perceptions and beliefs of Chuukese migrant women regarding barriers to health care and the factors that influence their health-seeking behaviors. The focus group method was appropriate for the research focus and purposes of this study. Focus groups can provide a voice for those who are socially marginalized and are an effective means of learning about participants' experiences and perspectives (Halcomb, Gholizadeh, DiGiacomo, Phillips, \& Davidson, 2007).

\section{Data Collection}

Prior to conducting the focus groups, the researcher held a pilot group meeting with Chuukese women to test and refine the demographic questionnaire and focus group guide. Additionally, a sociologist from the University of Hawaii, specializing in Chuukese culture, reviewed the focus group questions for appropriateness and clarity. The focus group questions and demographic questionnaire were available in Chuukese and English. The Micronesian Language Institute at the University of Guam translated the demographic questionnaire, consent form, and focus group questions. The Micronesian Language Institute is a regional leader in the area of Micronesian languages (Micronesian Language Institute, 2006). 
Asian/Pacific Island Nursing Journal, Vol. 2, Iss. 1 [2017], Art. 3

Table 2. Themes from Data Analysis

\begin{tabular}{lll}
\hline Theme & Categories & Subcategories \\
\hline $\begin{array}{l}\text { Barriers to Seeking and Main- } \\
\text { taining Health }\end{array}$ & $\begin{array}{l}\text { Financial Concerns } \\
\text { Difficulty Obtaining Care }\end{array}$ & $\begin{array}{l}\text { Lack of transportation } \\
\text { Long wait times in health care facilities } \\
\text { Inability to communicate with health care pro- } \\
\text { viders } \\
\text { Cistrust resulting from communication barriers }\end{array}$ \\
& $\begin{array}{l}\text { Communication Issues } \\
\begin{array}{l}\text { Social and Cultural Factors In- } \\
\text { fluence Health-seeking Behav- } \\
\text { iors }\end{array}\end{array}$ & $\begin{array}{l}\text { Use of Traditional Chuukese Medicine } \\
\text { Lack of Preventive Care } \\
\text { Confidentiality Concerns } \\
\text { Feelings of Mistreatment }\end{array}$ \\
\hline
\end{tabular}

A Chuukese female translator with experience translating for clients accessing health care services in Guam was present during the focus groups. Prior to the start of each group, the translator assisted participants as needed in completing the demographic questionnaire. Data included the year the person was born, years lived in Guam, years of education, the number of biological children, primary language spoken in the home, insurance status, income (range), the island of origin, and usual source of health care.

The researcher conducted the focus groups and the translator restated the questions in Chuukese (Table 1). A trained note-taker documented the seating arrangement, order in which participants spoke, eye contact, and other nonverbal behaviors. Both the translator and the note-taker were present at all focus group sessions. The focus groups were limited to five women. Focus group sessions lasted from 1 to 3 hours per group, with an average duration of 90 minutes per group. Focus groups were conducted over a 6-month period until saturation was reached. Saturation is achieved when the data are repeating and no new themes have risen from the data collection (Streubert Speziale \& Carpenter, 2007). In addition to the focus group questions, data was obtained from debriefing sessions held after each focus group. The translator and note-taker were also present. Return visits to the participants for verification of findings lasted 30 minutes to 1 hour, with an average duration of 40 minutes per session.

\section{Data Analysis}

Focus group transcripts were translated by a Chuukese translator from the Guam Department of Public Health and Social Services. Focus group data analysis occurred concurrently with the data collection procedures. Data were analyzed using qualitative content analysis. The researcher generated codes from the data, and analysis was a reflexive process. Data collection and analysis occurred simultaneously and both steps affected each other (Sandelowski, 2000). The researcher reviewed the digital recordings of the focus group, and the transcripts multiple times. The transcripts were entered in Atlas.ti 5.2 for data management and analysis. Significant statements were identified and extracted from the transcripts. The statements from all transcripts were analyzed to determine broad meanings. Codes were created based on the combined data from all focus groups and sorted into categories. Upon further analysis, subcategories within the broader categories were identified. A methodological log detailed the analysis and decisionmaking process.

Back-translation was performed by a translator with experience working in the Guam legal and mental health care systems. Back-translation was completed with the exact content of each focus group back-translated from English into Chuukese for the purpose of assuring credibility and reliability of the data. An external reviewer, the sociologist from the University of Hawaii regarded for her work with Chuukese in Hawaii and Guam, examined the findings and interpretations to establish dependability and confirmability of the data. The researcher verified the findings with the focus group participants after the external review was completed. Rich data was gleaned from the focus group interviews, field notes, debriefing, and verification of findings with the participants and the external reviewer.

\section{Results}

The researcher conducted five focus groups with a total of 21 Chuukese women participants. The average age of the participants was 39 years (ranged from 21 to 71 years old). All participants reported speaking Chuukese in their home. The educational background of the participants was reported as $28.6 \%$ completed grade school, $57.1 \%$ completed high school, and three of the women had completed the 11th grade. All participants reported a total household income less than $\$ 10,000$ per year. The average family size was seven people with an average of four children. Public health centers were identified by 16 of the 21 
women as their usual source for obtaining care. The local government hospital or the military hospital was the usual source of health care for two of the women. Three women reported their usual source of health care was either the local government hospital or one of the public health centers. The participants lived in Guam an average of 10.1 years (ranging from 3 to 22 years).

The themes that emerged were barriers to seeking and maintaining health and social and cultural factors influencing health-seeking behaviors (Table 2). The categories identified in barriers to seeking and maintaining health included (a) financial concerns, (b) difficulty obtaining care, and (c) communication issues. The theme of social and cultural factors influence health-seeking included the categories of (a) use of traditional Chuukese medicine, (b) lack of preventive care, (c) confidentiality concerns, and (d) feelings of mistreatment.

\section{Barriers to Seeking and Maintaining Health}

The common barriers to health care by the focus group participants were (a) financial concerns (lack of health care insurance, inability to meet copayment requirements), (b) difficulty obtaining care (transportation, long wait times), and (c) communication issues (inability to communicate with health care providers and mistrust between patients and health care providers resulting from communication barriers). Several women commented that these barriers made it difficult to seek health care and most did not seek care unless they were ill. Only one of the 21 participants identified preventive care as a part of her health-seeking behaviors.

\section{Financial Concerns}

Among the five focus groups, four groups identified lack of health insurance as a major barrier. Participants (whether insured or uninsured) identified financial barriers such as the issue of co-payments required for some services:

For Medicaid, they tell us how much to pay for co-payment. For example, if the medicine costs $\$ 20$, they would pay $\$ 10$ and I would pay $\$ 10$. For that, we wait until we have money, but when we have the money the prescription expired already because it's been a long time that we've been holding onto it.

\section{Difficulty Obtaining Health Care}

Many of the participants described the problem of transportation as one of the main barriers to seeking health care. Women in each of the five focus groups identified this barrier. One woman who reported having private insurance coverage, described transportation as the only barrier to her and her family's health-seeking behaviors:

For us there aren't any problems because we have insurance, except transportation is one issue we face trying to seek health care. Now our car is broken down. So now I have to cancel my appointment tomorrow. I never ride on the public transit.

A subcategory identified was long wait times. Women in four of the five groups identified long wait times when trying to obtain care in the hospital or clinical setting. Women expressed frustration with the long wait times and perceived them as excessive. When describing their experiences at the emergency room, the women perceived that the long wait times were an indication of lack of concern on the part of the health care workers. The following statement described the long wait experienced by one woman in the emergency room:

That is one problem, the long wait. It seems like they don't care about us. We go in and sit from morning to afternoon, we get hungry, cold. One time I came and waited until almost night. I came by and asked the nurses how long it would take. They would reply: 'go back and have a seat and just wait'. I almost just walked out.

\section{Communication Issues}

\section{Inability to communicate with providers.}

Participants in all groups described their inability to communicate with health care providers. Many women reported the need to bring a family member who could speak English with them, or if no English-proficient family member was available, the women spoke of trying their best to communicate. One woman even offered this statement, feeling that workers treat the Chuukese differently because of the language barrier: "Maybe they skip us for those that speak English." Another woman stated, "It is good for those who speak English, but for others it is hard. They have to bring someone who can translate for them." Several women voiced concern that the lack of translators prevented some Chuukese migrants from seeking health care services.

The government-funded civilian hospital in Guam does not have translators in the emergency room; however, employees who speak Chuukese may be called upon when needed based on the health care worker's judgment. The health care system in Guam continues to rely on family members or friends to translate, if available. The hospital utilizes Chuukese employees to translate when the health worker feels it is necessary. These Chuukese employees are not hired as translators but are utilized as part of a translator pool as needed. 


\section{Mistrust resulting from communication bar-} riers.

Another important finding was the language barrier and miscommunication occurring between patients and the health care providers. This miscommunication contributed to feelings of mistrust perceived by the women. One woman gave an account of her experience in the emergency room of the local hospital. She interpreted a physician's comment literally, and this miscommunication led to her mistrust of the physician and treatment prescribed. This incident provoked strong feelings and the woman brought it up several times during the focus group:

The skin all over my body was very swollen. I went to the hospital and the doctor said that is an infection-just give the trick. I don't know what kind of trick. I was praying and asked God to touch his heart so that he can feel how much pain I have. That is the only thing that I did that night. Then they gave me the paper for the medicine. I went to the pharmacy, I bought the medicine and it did not work. There is no use for me to go back to the hospital. They said they are going to do the trick. So what kind of trick are they going to do? She paused for a minute, and then went on. They really said that. That's the word coming out from the doctor's mouth. "The trick."

And later in the focus group, she again referred to the incident:

And the second time I went there last April, and the doctor said the sores are an infection and we're going to do the trick. I don't know what kind of trick. That's the thing that stuck in my brain.

Perhaps the practitioner used an idiom such as "This should do the trick" referring to the medication he prescribed to treat the skin ailment. The researcher cannot verify this; however, it is apparent that the perception of the woman was that the practitioner was going to play a trick on her. This led to distress for the woman and mistrust of the practitioner. The comments by the participant when the physician used the word 'trick' illustrated the complexities of language and powerfully demonstrated how miscommunications can occur with distressing consequences for the non-English speaking patient.

\section{Social and Cultural Factors Influence Health-seeking Behaviors}

\section{Use of Traditional Chuukese Medicine}

Women in four of the five groups reported using some form of Chuukese medicine to treat their family members. The women in the group who did not use Chuukese medicine verbalized their understanding of how others use Chuukese medicine: "As for me, I don't use Chuukese medicine. But I know that the Chuukese that do use Chuukese medicines will go to the hospital and when they are not healed, then they would try to use Chuukese medicine." Another participant from a different group described a similar practice:

When we go to the hospital and our illnesses are not cured or healed, then we would use our Chuukese medicine. It is a gift passed down from the elders. They can just see what the problem is and know what type of Chuukese medicine to use to cure the illnesses.

\section{Lack of Preventive Care}

A finding that emerged across all focus groups was the category of lack of preventive care. All but one of the women reported that they do not seek preventive care services. However, all women with children reported taking the children in for their immunizations and the women reported seeking prenatal care when they were pregnant.

\section{Confidentiality Concerns}

When women gave suggestions for how to improve care to Chuukese migrant women in Guam, many stated that they recommend providing Chuukese translators. Several women, however, described concerns that the translator may not keep information confidential. The first woman to identify the issue of confidentiality was a Chuukese woman who had worked as a nurse in Chuuk but moved to Guam to care for her sick, elderly parents. When asked what suggestions she could give to improve care for Chuukese migrant women in Guam, she answered, "You need to have translators." But then, smiling, she went on to explain:

Even though they want to have someone translate, some Chuukese don't want other Chuukese to know their problems..... we need help with translations so the people could better understand the importance of health care. But the problem is the possible leak of information of confidential health problems by the translators.

\section{Feelings of Mistreatment}

Women described feelings of being mistreated and several women used the word "afraid" or "scared" when describing how they felt regarding some health care workers. They described the fear as a barrier to health-seeking behaviors preventing some Chuukese from seeking help. A mistrust of health care 
workers and the health care system resulted from the women's perception of poor treatment. The communication barriers described earlier also contributed to this lack of trust.

Chuukese women are often identified by their long, floral skirts they wear as part of their day-to-day attire. The colorful skirts are a source of pride and cultural identity. When describing her experiences and thoughts on being mistreated, one participant stated in a low, sad tone of voice and with her eyes facing downward, "Sometimes I say to the women 'Let's not use our skirt so they won't know I'm Chuukese.' Sometimes I go out, I wear pants so they don't know I'm Chuukese." This statement powerfully demonstrated the concept of marginalization and not wanting to be identified as a member of a marginalized group. Chuukese women have a strong cultural tradition of wearing long skirts. The lower body is considered "private" and not to be shown by wearing short skirts or pants. Chuukese women are expected to maintain a modest appearance and should not demonstrate any behavior that may be viewed as having sexual connotations. In order to maintain the incest taboo, a woman must maintain modesty in appearance, clothing, actions, and even in her presence (Moral, 1998). This example of the Chuukese woman deciding to wear pants, rather than her traditional skirt, is powerful and is important when viewed within the cultural context. Her nonverbal behavior of lowering her head as she spoke further emphasized to the researcher the significance of her comment.

\section{Discussion}

The barriers to seeking and maintaining health included financial concerns, difficulty obtaining care related to lack of transportation, long wait times, and communication barriers. The existing literature on Micronesian populations in the United States was consistent with the identification of transportation difficulties, financial concerns, and communication issues as barriers to seeking health care (Aitaoto, Braun, Estrella, Epeluk, \& Tsark, 2012; Aitaoto, Tsark, Tomiyasu, Yamashita, \& Braun, 2009; Shoultz et al., 2007; Williams \& Hampton, 2005). In a study of intimate partner violence, researchers cited lack of employment, poverty, and low-income as factors that influenced health-seeking behaviors of Chuukese women in Hawaii (Aitaoto et al., 2009). Limited financial resources for meeting co-payment requirements and lack of health insurance were barriers to breast cancer screening identified by Micronesian women in Hawaii. Women revealed that although they wanted to have a mammogram, they were reluctant to make appointments due to transportation and financial concerns (Aitaoto et al., 2012).
The literature supported the findings of the inability to communicate as a barrier to health-seeking behaviors (Aitaoto et al., 2009, 2012; Choi, 2008; Ramsey, Davis, \& French, 2012; Williams \& Hampton, 2005). In a study of Marshallese migrants living in the United States, communication barriers led to frustration during health care encounters. Marshallese were less likely to seek health care if a translator was not available (Williams \& Hampton, 2005). Ramsey et al. (2012) found that $71 \%$ of Chuukese respondents living in Hawaii preferred a family member or a friend to interpret their health care rather than telephone interpreters or in-person professional translators. However, the need for hiring and training of in-person interpreters was recommended to meet the growing needs of non-English speakers. Further study of the use of trained professional interpreters rather than family members or friends with the Micronesian population was recommended (Ramsey et al., 2012). In this study, the lack of appropriate translators in health care facilities was cited as a problem by the women. Furthermore, the women identified that the practice of using family members as translators was not adequate to meet the communication needs when seeking health care.

A finding unique to this study was the concern that the use of Chuukese translators may pose a barrier because of fears that confidentiality may be breached. The provision of translators for Chuukese migrants as a means of diminishing barriers is recommended in the literature (Choi, 2008; Williams \& Hampton, 2005). The finding, however, that the use of Chuukese translators can also pose barriers was not evident in the published literature.

The use of traditional Chuukese medicine was not described in the literature on Micronesians and none of the studies identified the use of cultural health practices as a barrier to seeking health care. One study addressed the use of Western medical practices rather than Marshallese cultural practices by migrants who moved to Hawaii in search of health care not available in their home country (Choi, 2008). The Chuukese women in this study described both a reliance on Western medical care as well as some use of Chuukese medicines for specific illnesses. Chuukese migrant women in Guam did not exclusively rely on Chuukese medicines or health practices, and women reported differing uses of Chuukese medicines by migrants in Guam. The use of traditional medicines warrants further research.

Chuukese women in this study described health-seeking patterns that did not include preventive care beyond prenatal care and childhood immunizations. Even women with identified health conditions reported not seeking health care on a regular basis. This behavior was typical of the women as their major 
concern was for their children rather than their own health care needs. It is also conceivable that they lacked understanding of their own health care needs. The focus on the health of the children is part of the cultural role of women. The lack of preventive care and awareness of health screening by Micronesians is supported in the literature (Choi, 2008; Ramsey et al., 2012; Wong \& Kawamoto, 2010). In studies of Chuukese women in Hawaii and barriers to seeking cancer screening services, lack of screening awareness was evident. Researchers recommended education and the need for culturally tailored education (Ramsey et al., 2012; Wong \& Kawamoto, 2010).

Study findings of the perception of mistreatment by Chuukese women are not widely reflected in the literature. Two studies involving Micronesians identified feelings of prejudice and discrimination perceived by study participants (Pobutsky et al., 2009; Williams \& Hampton, 2005). Marshallese participants voiced a lack of trust and perceptions of mistreatment; however, Williams \& Hampton (2005) related this mistrust to the historical destruction of their homeland by the U.S. military. This experience differs from the Chuukese experience in Guam. Women related the mistrust resulting from communication barriers. Fear described by women was related to previous negative experiences with health and social service workers. The findings of this study are similar to studies of Micronesian migrants in Hawaii that identified feelings of mistreatment and discrimination when seeking help from health, education, and public welfare agencies (Pobutsky et al., 2009). The awareness of perceptions of Micronesian migrants and the effect it may have on their health-seeking behaviors can assist nurses and other health care workers in caring for this population.

\section{Limitations}

The socioeconomic background of the study participants, convenience sample, and the sole focus on Chuukese women were limitations of this study. All participants had limited educational backgrounds, which may have influenced the findings. The focus on women is a limitation; however, gender norms and avoidance behaviors limited the ability of the researcher to interact with Chuukese males. Therefore, the research was limited to women. The findings cannot be generalized to men or to all Chuukese migrants. The small sample size and the geographic location of the study to Guam limit transferability to other Chuukese migrants in different locations.

The inability of the researcher to speak and understand the Chuukese language was another limitation. Efforts were taken to minimize this limitation by using a female Chuukese translator, back translation, and member checking. The back translator noted that the women seemed to speak freely to the researcher despite the language limitation. The confidentiality concerns raised by the women reinforced the appropriateness of a non-Chuukese researcher. Despite the limitations, this study added new information to the body of knowledge of Micronesian migrants in the United States, and in particular, of Chuukese migrants in Guam.

\section{Implications and Recommendations}

Participants provided recommendations to improve care to the migrant population including providing translators, establishing outreach activities to provide health care services in the villages, and improving the transportation system. The study findings support that health-seeking behaviors are affected by factors more complex than merely financial and insurance barriers. Nurses and health care providers can improve care for the Chuukese by being aware of the communication barriers and resultant mistrust that can occur due to miscommunication. Educating nurses and other health professionals about the Chuukese culture may facilitate the provision of culturally sensitive care that fosters the development of a trusting relationship. This trusting relationship provides a strong foundation from which to positively effect changes in health-seeking and health-maintaining behaviors.

This study revealed an important finding regarding confidentiality concerns when working with Chuukese translators, which warrants further study. It was clear from validation with the Chuukese women that this was an important issue to address when working with Chuukese translators and the Chuukese clients seeking care. Further research can be done to validate the findings of this study and to examine if confidentiality when using translators from the same ethnic group is a concern for other Micronesian migrant groups.

Further nursing research can be conducted to add to the knowledge of Chuukese and other compact migrants; such as research on the meaning of health to Chuukese migrants and studies on barriers and healthseeking behaviors of other Micronesian groups. These can contribute to the information that may be used to decrease disparities and improve health outcomes.

\section{Conclusion}

Social and cultural factors influenced healthseeking behaviors and this study provides a view of the unique perceptions of Chuukese migrant women in Guam; it represents one of the first times their voices have been heard. Participants expressed an urgent need for improvement in the health and social service 
systems in Guam and provided recommendations for changes. Study findings may assist policy makers, nurses, and other health professionals in planning, developing, and implementing effective strategies to improve health outcomes and decrease disparities affecting Chuukese migrants.

\section{References}

Aitaoto, N., Braun, K. L., Estrella, J., Epeluk, A., \& Tsark, J. (2012). Design and results of a culturally tailored cancer outreach project by and for Micronesian women. Preventing Chronic Disease, 9(E82). https://doi.org/10.5888/pcd9.100262

Aitaoto, N., Tsark, J. U, Tomiyasu, D. A, Yamashita, B., \& Braun, K. L. (2009). Strategies to increase breast and cervical cancer screening among Hawaiian, Pacific Islander, and Filipina women in Hawaii. Hawai'i Medical Journal, 68, 215-222.

Alur, P., Kodiyanplakkal, P., Del Rosario, A., Khubchandani, S., Alur, R., \& Moore, J. J. (2002). Epidemiology of infants of diabetic mothers in indigent Micronesian population-Guam experience. $\mathrm{Pa}$ cific Health Dialog, 9, 219-221.

Choi, J. Y. (2008). Seeking health care: Marshallese migrants in Hawai'i. Ethnicity \& Health, 13, 73-92. https://doi.org/10.1080/13557850701803171

Government of Guam, Office of the Governor. (2011). FY2010 Compact impact report. Hagåtña, Guam: Author. Retrieved from https://www.doi.gov/oia/ reports/Compact-Impact-Reports

Greico, E. M., Levin, M., Stroot, M., Samo, M., Sasamoto, D., Tellames, K., \& Edwin, R. (2003, January 15). The status of Micronesian migrants in 1998: A study of the impact of the Compacts of Free Association based on censuses of Micronesian migrants to Hawai ' $i$, Guam and the Commonwealth of the Northern Mariana Islands. Washington, DC: Office of Insular Affairs, Department of the Interior. Retrieved from http://www.pacificweb.org/DOCS/guam/compactimp98.pdf

Guam Bureau of Statistics \& Plans. (2005). 2004 Guam statistical yearbook. Hagåtña, Guam: Office of the Governor.

Guam Bureau of Statistics \& Plans. (2015). 2014 Guam statistical yearbook. Hagåtña, Guam: Office of the Governor.

Guam Department of Public Health and Social Services. (2014). Guam community health assessment. Mangilao, Guam: Author.

Guam Housing and Urban Renewal Authority. (2016). 2016 Guam homeless point-in-time final count [Press release]. Retrieved from http://www.ghura.org

Haddock, R. L., Talon, R. J., \& Whippy, H. J. D. (2006). Ethnic disparities in cancer mortality among residents of Guam. Asian Pacific Journal of Cancer Prevention, 7, 411-414.

Haddock, R. L., Whippy, H. J. D., Talon, R. J., \& Montano, M. V. (2009). Ethnic disparities in cancer incidence among residents of Guam. Asian Pacific Journal of Cancer Prevention, 10, 57-62.

Halcomb, E. J., Gholizadeh, L., DiGiacomo, M., Phillips, J., \& Davidson, P. M. (2007). Literature review: Considerations in undertaking focus group research with culturally and linguistically diverse groups. Journal of Clinical Nursing, 16, 10001011. https://doi.org/10.1111/j.1365-2702.2006. 01760.x

Hezel, F. X. (1992). The changing family in Chuuk: 19501990. Retrieved from http://www.micsem.org/ pubs/articles/famchange/frames/chngfamfr.htm

Hezel, F. X. (2001). The new shape of old island cultures: A half century of social change in Micronesia. Honolulu, HI: University of Hawai'i Press.

Hezel, F. X., \& Levin, M. J. (2012). Survey of Federated States of Micronesia migrants in the United States including Guam and the Commonwealth of Northern Mariana Islands (CNMI). Palikir, Pohnpei: Federated States of Micronesia (FSM) Office of Statistics, Budget and Economic Management. Retrieved from https://prd.psc.isr.umich.edu/files/ Resources_Report\%20on\%20PI\%20Jurisdictions.pdf

Micronesian Language Institute. (2006). About the Micronesian Language Institute. Retrieved from http://www.uog.edu/mli/index-about-detail.html

Moral, B. (1998). The Chuukese women's status: Traditional and modern elements. In V. Keck (Ed.), Common worlds and single lives: Constituting knowledge in Pacific societies (pp. 273-284). New York: Berg.

Pacific Resources for Education and Learning. (2005). Pacific service region: Chuuk, Federated States of Micronesia. Retrieved from http://prel.org

Pobutsky, A. M., Buenconsejo-Lum, L., Chow, C., Palafox, N., \& Maskarinec, G. G. (2005). Micronesian migrants in Hawaii: Health issues and culturally appropriate, community-based solutions. Californian Journal of Health Promotion, 3(4), 59-72.

Pobutsky, A. M., Krupitsky, D., \& Yamada, S. (2009). Micronesian migrant health issues in Hawaii: Part 2: An assessment of health, language and key social determinants of health. Californian Journal of Health Promotion, 7(2), 32-55.

Ramsey, K. W., Davis, J., \& French, G. (2012). Perspectives of Chuukese patients and their health care providers on the use of different sources of interpreters. Hawai'i Journal of Medicine \& Public Health, 71, 249-252.

Sandelowski, M. (2000). Whatever happened to qualitative description? Research in Nursing \& Health, 23, 334-340. https://doi.org/10.1002/1098-240X (200008) 23:4<334:: AID-NUR9>3.0.CO;2-G

Shoultz, J., Magnussen, L., Hansen, K., Selifis, S., \& Ifenuk, M. (2007). Intimate partner violence: Perceptions of Chuukese women. Hawai'i Medical Journal, 66, 268-271. 
Streubert Speziale, H. J., \& Carpenter, D. (2007). Qualitative research in nursing: Advancing the humanistic imperative (4th ed.). Philadelphia: Lippincott, Williams \& Wilkins.

Tan, C., Haumea, S., Juarez, D. T., \& Grimm, C. (2014). A descriptive study of Marshallese and Chuukese patients with diabetes in Hawaii. Hawai'i Journal of Medicine \& Public Health, 73, 168-171.

The Salvation Army, The Guam Housing and Urban Renewal Authority. (2007). Guam homeless coalition. Point-in-time homeless count: January 25, 2007. Sinajana, Guam: Author.

The Salvation Army USA Western Territory. (2003, May 8). Getting to know Chuuk. New Frontier. Retrieved from http://www.newfrontierchronicle.org/ getting-to-know-chuuk/
U.S. General Accounting Office. (2016). Compacts of free association: Issues associated with implementation in Palau, Micronesia, and the Marshall Islands (GAO 16-550T). Washington, DC: Author.

Williams, D. P., \& Hampton, A. (2005). Barriers to health services perceived by Marshallese immigrants. Journal of Immigrant Health, 7, 317-326. https://doi.org/10.1007/s10903-005-5129-8

Wong, V. S., \& Kawamoto, C. T. (2010). Understanding cervical cancer prevention and screening in Chuukese women in Hawai'i. Hawai'i Medical Journal, 69(Suppl. 3), 13-16.

Yamada, S., \& Pobutsky, A. (2009). Micronesian migrant health issues in Hawaii: Part 1: Background, home island data, and clinical evidence. Californian Journal of Health Promotion, 7(2), 16-31. 